\title{
The MAC-BIS50-tetanus of desflurane decreases by aging
}

\author{
Masahide Fujita, MD, Shinichi Inomata, MD, Makoto Tanaka, MD. \\ Department of Anesthesiology, University of Tsukuba, Japan.
}

\section{BACKGROUND AND GOAL OF THIS STUDY}

Intraoperative awakening is one of the complications which should be avoided. The minimum alveolar concentration of volatile anesthetics is an important factor in the suppression of biological response to nociceptive stimulation. A bispectral index (BIS) monitor is valuable for the maintenance of appropriate sedation; we have previously reported the minimum alveolar concentration (MAC) of desflurane at which the BIS index does not exceed 50 during nociceptive stimulation (MAC-BIS50tetanus) was $4.27 \%(95 \% \mathrm{Cl}: 4.15-4.39 \%)$ in the adult patients (aged from 31 to 65 years). In this study, we investigated MAC-BIS50-tetanus in the elder patients (aged over 65 years).

\section{METHODS}

- The patients undergoing scheduled operation were recruited to this study, and written informed consent was obtained from all of them.

- The patients who had psychological disease and received sedatives were excluded.

- Anesthesia was induced with sevoflurane and $60 \%$ of nitrous oxide in $40 \%$ of oxygen and air. After the administration of rocuronium $(0.6 \mathrm{mg} / \mathrm{kg}$ ), a supra-glottic device (LMA or igel) was introduced.

- Then, administration of nitrous oxide and sevoflurane was then terminated, and we confirmed that the pre-determined end-tidal concentration of desflurane maintained for 10 minutes.

- The neuromuscular monitoring was used as a nociceptive stimulator; the altitude of the stimulation was $80 \mathrm{~mA}$ for 10 seconds, which is reported to be equal to skin incisional pain in the ulnar nerve ${ }^{1)}$.

- The BIS index was recorded every 10 seconds for 1 minute from beginning 1 minute after the stimulation.

- We defined the average of 6 BIS values as the BIS index for each patient.

- The MAC-BIS50-tetanus was determined using Dixon's upand-down method.

\section{RESULTS}

- Nineteen patients participated.

- Their mean age, height, and weight were $71.8 \pm 4.7$ years, $156.9 \pm 11.4 \mathrm{~cm}$, and $56.6 \pm 10.1 \mathrm{~kg}$, respectively (Table 1).

- The MAC-BIS50-tetanus was 3.53\% (95\%Cl: $3.38-3.69 \%)$ according to Dixon's up-and-down method ${ }^{2}$ (Figure 2).

\section{Table 1. Demographic data}

\begin{tabular}{|c|c|}
\hline $\mathrm{n}(\mathrm{M} / \mathrm{F})$ & $19(8 / 11)$ \\
\hline Age $($ Year $)$ & $71.8 \pm 4.7$ \\
\hline Height $(\mathrm{cm})$ & $156.9 \pm 11.4$ \\
\hline Weight $(\mathrm{kg})$ & $56.6 \pm 10.1$ \\
\hline
\end{tabular}

Data are presented as mean \pm SD.
Figure 1. Timing of stimulation and data collection

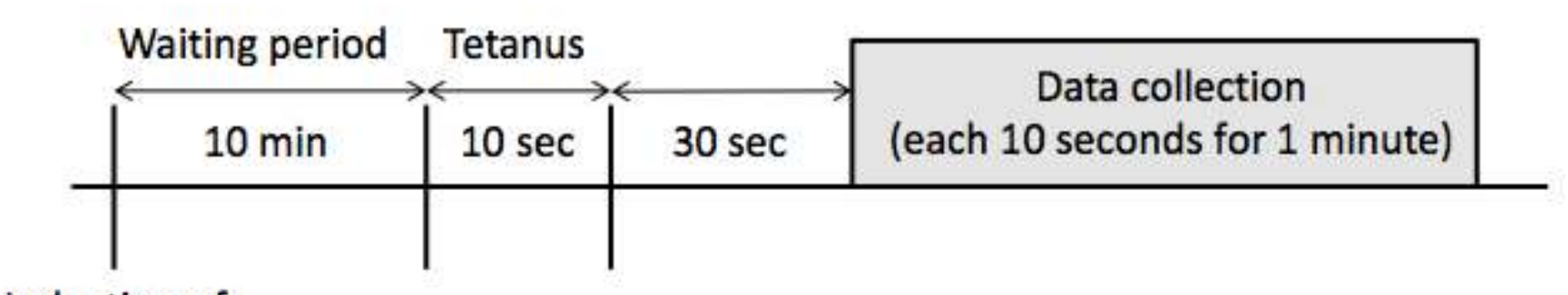

Induction of

anesthesia

Figure 1. Timing of stimulation and data collection. Anesthesia was induced with nitrous oxide and sevoflurane. Thereafter, a 10-min waiting period was allowed for transition to pure desflurane anesthesia. 30 seconds after a 10 -sec tetanic stimulation, BIS index were collected each 10 seconds for 1 minute.

Figure 2. The BIS index response of consecutive 20 patients to tetanus stimulation with the up and down method

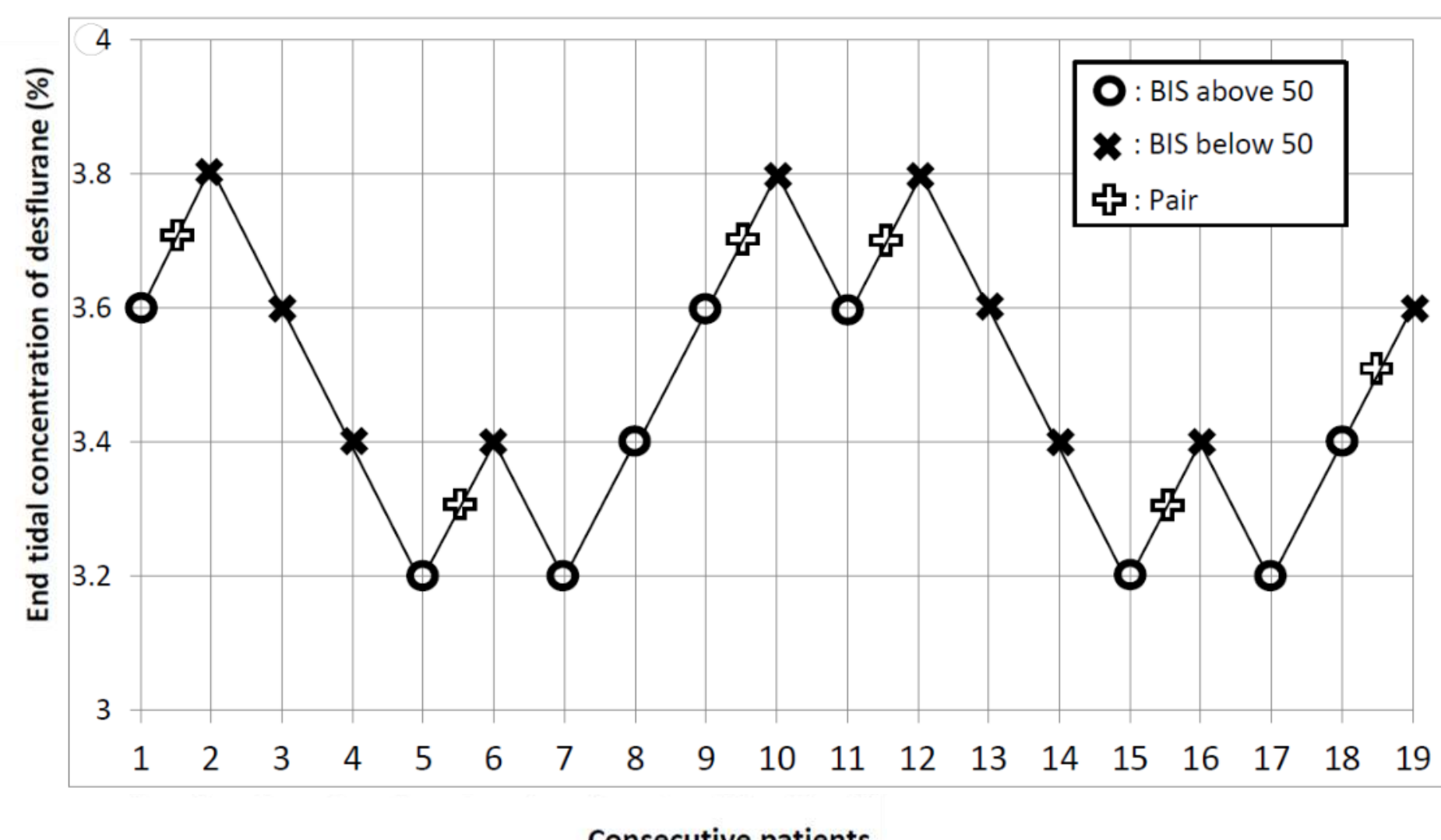

Consecutive patients

\section{CONCLUSION}

The MAC-BIS50-tetunus of desflurane was 3.53\% $(95 \% \mathrm{Cl}: 3.37-3.69 \%)$ in the elder patients. It has been reported that MAC-BIS50 is $2.75 \%(2.50-3.00)$ in the elder patients ${ }^{3}$. MAC-BIS50-tetanus was equivalent to $0.67 \mathrm{MAC}$. It was significantly lower than that of middle aged patients group. In elder patients, when the end-tidal concentration of desflurane is $3.53 \%$, the BIS index is suggested to exceed 50 in half of the patients during nociceptive stimulation. 